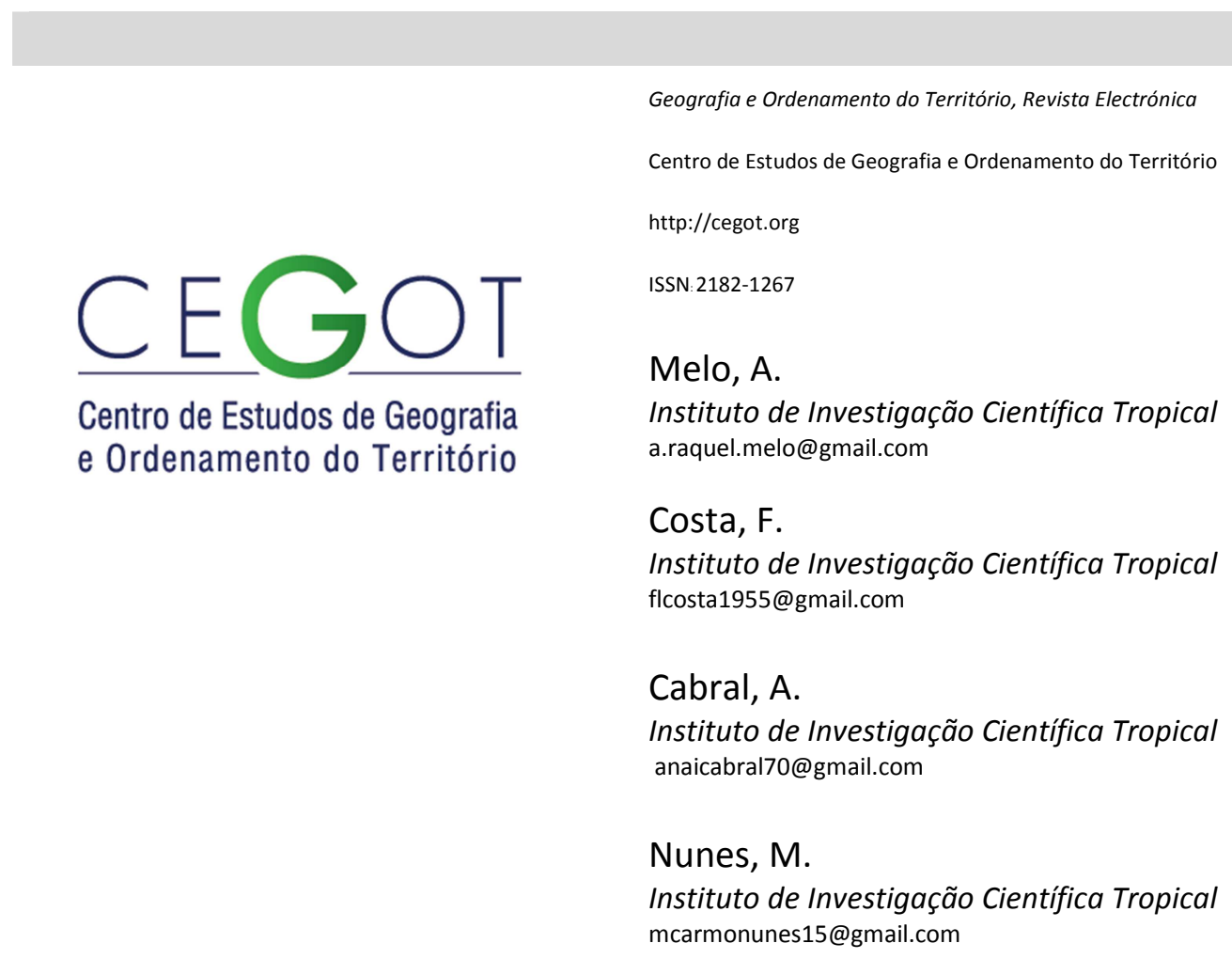

\title{
Acessibilidade e ocupação do solo em regiões de fronteira da Guiné-Bissau
}

Referência: Melo, A. et. al (2014). Acessibilidade e ocupação do solo em regiões de fronteira da Guiné-Bissau. Revista de Geografia e Ordenamento do Território (GOT), n. 6 (dezembro). Centro de Estudos de Geografia e Ordenamento do Território, p. 223-239

\section{Resumo}

Este estudo tem como objectivo avaliar a acessibilidade da rede viária e analisar o coberto do solo nas regiões de fronteira da Guiné-Bissau, utilizando técnicas de detecção remota, Sistemas de Informação Geográfica (SIG) e conceitos básicos de análise de redes, tendo sido desenvolvido no âmbito do projecto "Tecnologias Geoespaciais na Demarcação e Gestão da Fronteira da Guiné-Bissau - GEOBOUND"1

A análise centra-se em duas regiões onde a linha de fronteira foi demarcada, em parte, por vales de rios, uma localizada no sector norte com o Senegal e outra no leste com a GuinéConacri. Os resultados mostram que a rede viária e o coberto do solo têm continuidade e similitude entre os países em cada uma das áreas, em termos de acessibilidade transfronteiriça, não existindo interferência dos cursos de água.

Palavras-Chave: Regiões de Fronteira; Acessibilidade; Coberto do solo; SIG; Guiné-Bissau.

\footnotetext{
${ }^{1}$ Financiado pela Fundação para a Ciência e a Tecnologia (FCT), PTDC/ATP-GEO/4645/2012.
} 


\begin{abstract}
This study aims to evaluate the road network's accessibility and to analyze land cover in borderlands of Guinea Bissau, using techniques of remote sensing, Geographic Information Systems (GIS) and basic concepts of network analysis and was developed within the project "Geospatial Tools on Demarcation and Management of Guinea Bissau Boundary GEOBOUND"1.

The analysis focuses on two regions where the boundary is, in part, demarcated by river valleys, one located in the northern sector with Senegal and another in the eastern sector with Guinea-Conakry. The results show that the road network and land cover have continuity between countries and also reveal a certain similarity, in each of the regions, in terms of cross-border accessibility, without the interference of the valleys.
\end{abstract}

Keywords: Borderlands; Accessibility; Land cover; GIS; Guinea Bissau.

\title{
1. Introdução
}

Na África pré-colonial as organizações políticas e sociais (família alargada, tribo, etnia e nação) eram muito diversificadas mas bem marcadas. O espaço territorial e a definição de fronteira, separando entidades políticas, eram estabelecidos por factores, como o sistema político e económico ou a proporção entre a terra e a população, e não dependiam de unidades étnicas, culturais ou linguísticas. As fronteiras sempre existiram delimitando espaços geográficos de acordo com as organizações políticas e sociais locais, que englobavam várias etnias e diversas línguas, sendo as fronteiras étnicas e políticas raramente coincidentes (Amaral, 1994).

Os espaços territoriais de 52 dos estados africanos foram delimitados pelas suas administrações coloniais da Europa, após a Conferência de Berlim, em 1885, tendo sido a maioria concluída nas duas décadas seguintes. O Egipto e a Etiópia, as mais antigas entidades políticas da história do Homem, são as únicas excepções (Amaral, 1995).

África está dividida por 109 fronteiras internacionais, cerca de metade das quais são definidas por coordenadas geográficas, sendo um terço por linhas geométricas e um quarto por elementos naturais, como limites de bacias hidrográficas, linhas de água ou talvegues, montanhas ou linhas de cumeada. As linhas de fronteira têm uma grande diversidade de formas, combinando sectores ao longo dos paralelos e meridianos, segmentos de recta com várias orientações, arcos de círculo, linhas de água e de interflúvios e alinhamentos de relevo (Amaral, 1985; Amaral, 1994). 
Os novos países africanos, como a Guiné-Bissau, adoptaram o modelo de estado nação europeu ao qual tentaram ajustar as sociedades pluriculturais e multi-étnicas, que integram - espaço definido pelas fronteiras artificiais coloniais (Amaral, 1994). Esses países mantiveram uma certa tradição africana pré-colonial de espaços políticos com uma grande diversidade cultural, que integram várias línguas e etnias, havendo mesmo casos de coincidência dos limites fronteiriços coloniais com os de jurisdição de dirigentes locais africanos (Döpcke, 1999).

A maioria dos investigadores que se dedicaram ao estudo das fronteiras em África admitiu, no entanto, que os novos países independentes são verdadeiros puzzles pela sua multiplicidade de línguas e pela sua diversidade de etnias, sem uma história comum (Amaral, 1994). Em África existe um total de 834 grupos étnico-linguísticos, (Murdock, 1959), 358 dos quais se encontram distribuídos por mais do que um país (Michalopoulos e Papaioannou, 2011). A divisão de espaços culturais, associada ao elevado número de fronteiras com um traçado segundo linhas rectas, podem sugerir um total desrespeito pelas realidades sociais pré-coloniais na delimitação das fronteiras.

A Guiné-Bissau faz fronteira a norte com o Senegal, na região de Casamança, ao longo de cerca de $338 \mathrm{~km}$, e é caracterizada pela inexistência de acidentes naturais. A leste e a sudeste com a Guiné-Conacri, numa extensão de aproximadamente 386 km, foi delimitada por talvegues de curso de água e segmentos de recta.

A linha de fronteira divide espaços étnicos entre países vizinhos, como o dos fulas no leste, com a Guiné-Conacri, e os dos balantas, fulas e mandingas, no troço norte com o Senegal. A fronteira não constitui na realidade uma barreira, sendo muito permeável aos movimentos da população e ao tráfego de mercadorias com fins comerciais. A circulação transfronteiriça é frequente para desenvolver actividades agro-pecuárias quotidianas, aceder a mercados e a serviços ou participar em eventos culturais e religiosos, de acordo com vários estudos realizados (Fanchette, 2001; Arragain e Salliot, 2006; Tomás, 2010; Dione, 2013).

As actividades concertadas entre as populações de países vizinhos são frequentes e visam, por exemplo, o ordenamento agrícola de vales transfronteiriços (Tam-Tam, 2009) ou acções concretas em termos de segurança e resolução de pequenos delitos (Arragain e Salliot, 2006). A ocorrência de actividades comuns e de tráfego pedonal e de veículos são mais frequentes no caso particular da fronteira norte, sobretudo devido às afinidades étnico- 
linguísticas entre os povos da Guiné-Bissau e os da região de Casamança (Tomás, 2010). As frequentes deslocações transfronteiriças ocorrem ainda na dependência das condições do comércio em termos de mercado e preços, em particular nos mercados semanais de cada país (Fanchette, 2001). Encontra-se também na origem destas movimentações, a boa qualidade dos serviços prestados naquela região do Senegal, nomeadamente em termos de cuidados de saúde (Dione, 2013).

A fronteira é muito permeável pois, para além das ligações históricas e étnicas, não foi delimitada por acidentes naturais muito acentuados, particularmente no troço norte. Estes aspectos facilitam a acessibilidade que, por sua vez, associada à atractividade do comércio dos serviços, se reflectem no desenvolvimento da rede viária nas regiões transfronteiriças e na similitude de ocupação do solo entre os países vizinhos.

Em trabalho anterior, os mesmos autores (Costa et al., 2014) estudaram áreas onde a linha de fronteira não foi definida por acidentes naturais. Constataram que a fronteira não constitui uma barreira, pois a rede viária, a acessibilidade e o coberto do solo são semelhantes entre países limítrofes e têm continuidade transfronteiriça. No presente trabalho, na sequência daqueles resultados, decidiram analisar outras áreas em que a linha de fronteira foi delimitada, em parte, por cursos de água, para avaliar, deste modo, quais os possíveis impactos da fronteira na ocupação do território.

\section{2. Área de estudo e informação geográfica}

A selecção das áreas de estudo foi realizada de acordo com as características da fronteira e a informação geográfica existente. A fronteira terrestre entre a Guiné-Bissau e o Senegal não é delimitada por acidentes naturais, mas por segmentos de recta, sendo a topografia, de um modo geral, plana nas regiões fronteiriças (figura 1). Apenas existe um sector, de cerca de $10 \mathrm{~km}$, onde em pleno território do Senegal, o talvegue de um curso de água, a norte da região de Cuntima, tem um traçado paralelo à linha de fronteira com a GuinéBissau, a cerca de 500 m de distância desta. A fronteira com a Guiné-Conacri é delimitada por linhas de água em cerca de metade da sua extensão. A topografia nas regiões de fronteira é mais acidentada, excepto nos sectores leste e no mais próximo do litoral sul (figura 1). 


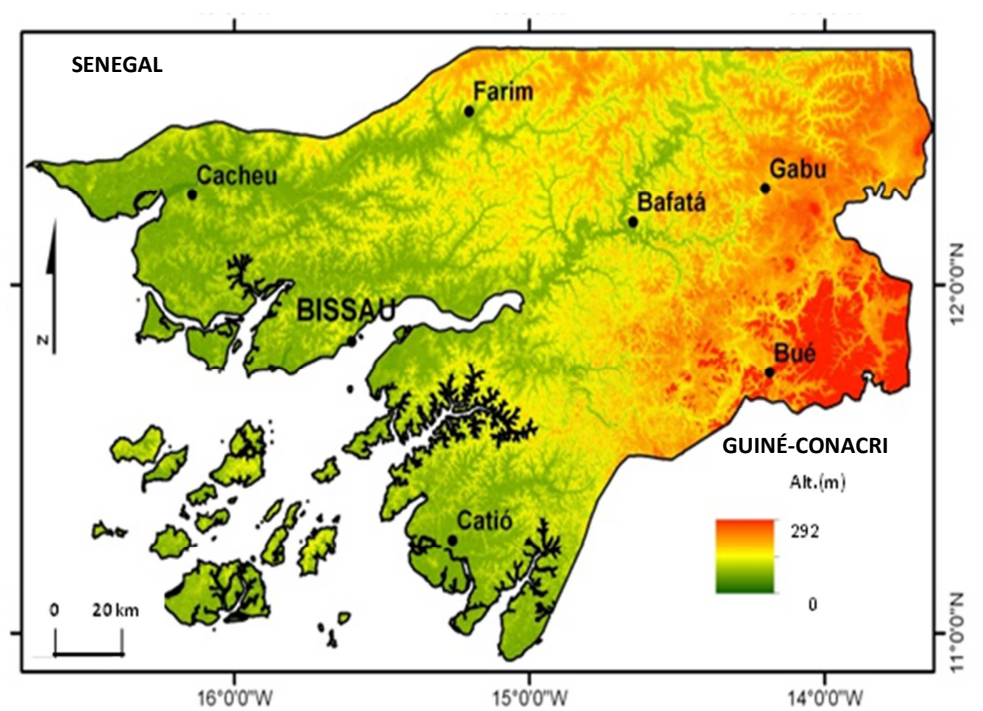

Figura 1 - Modelo digital de terreno da Guiné-Bissau.

Neste trabalho comparam-se as acessibilidades, bem como o coberto do solo em duas áreas de estudo da fronteira entre a Guiné-Bissau e cada um dos países vizinhos. O estudo das acessibilidades foi baseado na cartografia da Guiné-Bissau, na escala de 1:50000 (JMGIU/IICT, 1950-1965), a maior escala produzida, onde a delimitação da linha de fronteira e a posição dos respectivos marcos se encontram com uma maior precisão. Estas cartas contêm também informação, sobre a rede viária e aldeias, que se estende aos países limítrofes. Construiu-se, com estes tipos de informação, uma base de dados geográfica, em ambiente SIG. Os mapas de coberto do solo foram obtidos a partir de imagens Landsat Thematic Mapper Plus (ETM+), relativas ao ano de 2010, com uma resolução espacial de 30 m. Estes mapas foram reamostrados para um pixel de 25 metros, de forma a estabelecer a área mínima cartografada de 1 ha ( $4 \times 4$ pixels).

Para a obtenção dos indicadores de centralidade e acessibilidade seleccionaram-se dois polígonos com cerca de $20 \mathrm{~km}$ de comprimento e aproximadamente $2 \mathrm{~km}$ de largura, para cada lado da linha de fronteira (figura 2). 


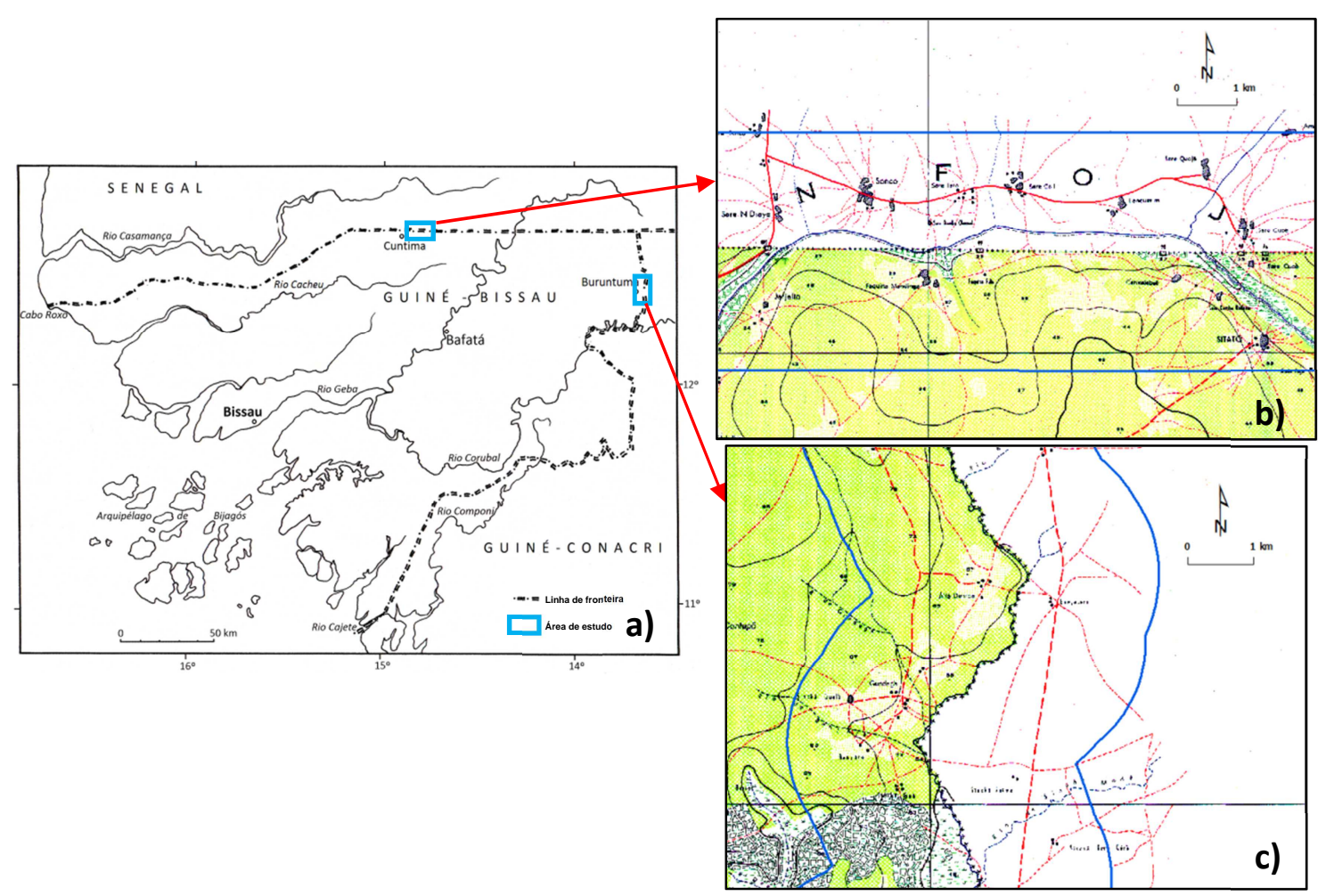

Figura 2 - Áreas de estudo: a) localização; b) extracto norte da fronteira com o Senegal; c) extracto leste com a Guiné-Conacri.

O comprimento dos polígonos foi definido para incluir dois sectores, um onde a linha de fronteira foi delimitada por talvegues de cursos de água e outro por segmentos de recta. Os cursos de água na área leste não constituem o limite fronteiriço apenas em cerca de $10 \mathrm{~km}$ de extensão e na área a norte restringem-se só a $10 \mathrm{~km}$ da região de fronteira. Perante este facto e para que as duas áreas de estudo possam ser comparáveis, optou-se por definir uma extensão máxima de $20 \mathrm{~km}$, condicionada pelo comprimento daqueles dois tipos de limites de fronteira. A sua largura ficou limitada a um total de $4 \mathrm{~km}$, uma vez que na cartografia de base a informação sobre a rede viária e aldeias nos países vizinhos abrange apenas uma extensão de cerca de $2 \mathrm{~km}$.

As áreas de estudo localizam-se na fronteira norte, com o Senegal, na região de Cuntima, e na leste, com a Guiné-Conacri, próximo de Buruntuma (figura 2). Estes sectores da fronteira encontram-se entre os que dispõem de maior fluxo transfronteiriço entre a Guiné-Bissau e os dois países vizinhos, o que se reflecte no elevado número de eixos viários. 


\section{Metodologia e resultados}

Este estudo tem como objectivos principais comparar as acessibilidades entre aldeias em duas regiões fronteiriças da Guiné-Bissau e avaliar a similitude do coberto do solo, entre os países limítrofes. Tem como objectivos específicos: contribuir para a caracterização das relações transfronteiriças, utilizando cartografia de base (aldeias e eixos viários) e imagens de satélite; analisar a distribuição espacial do povoamento entre países contíguos nas regiões de fronteira, recorrendo a Sistemas de Informação Geográfica (SIG) e a conceitos básicos de análise de redes (Teoria dos Grafos); avaliar o possível impacto da linha de fronteira no coberto do solo, utilizando técnicas de detecção remota.

\subsection{Avaliação de acessibilidade}

O método utilizado na análise da organização espacial do território baseou-se na teoria dos grafos, em função das aldeias e da rede viária, para cada uma das áreas de estudo. De acordo com esta teoria foram usados dois tipos de medidas: as de conectividade e ligação e as de acessibilidade e centralidade, conforme se esquematiza na figura 3.

Este estudo apoiou-se sobretudo em Sousa (2010) que sistematizou os aspectos fundamentais daquela teoria e desenvolveu aplicações SIG para a rede de transportes.

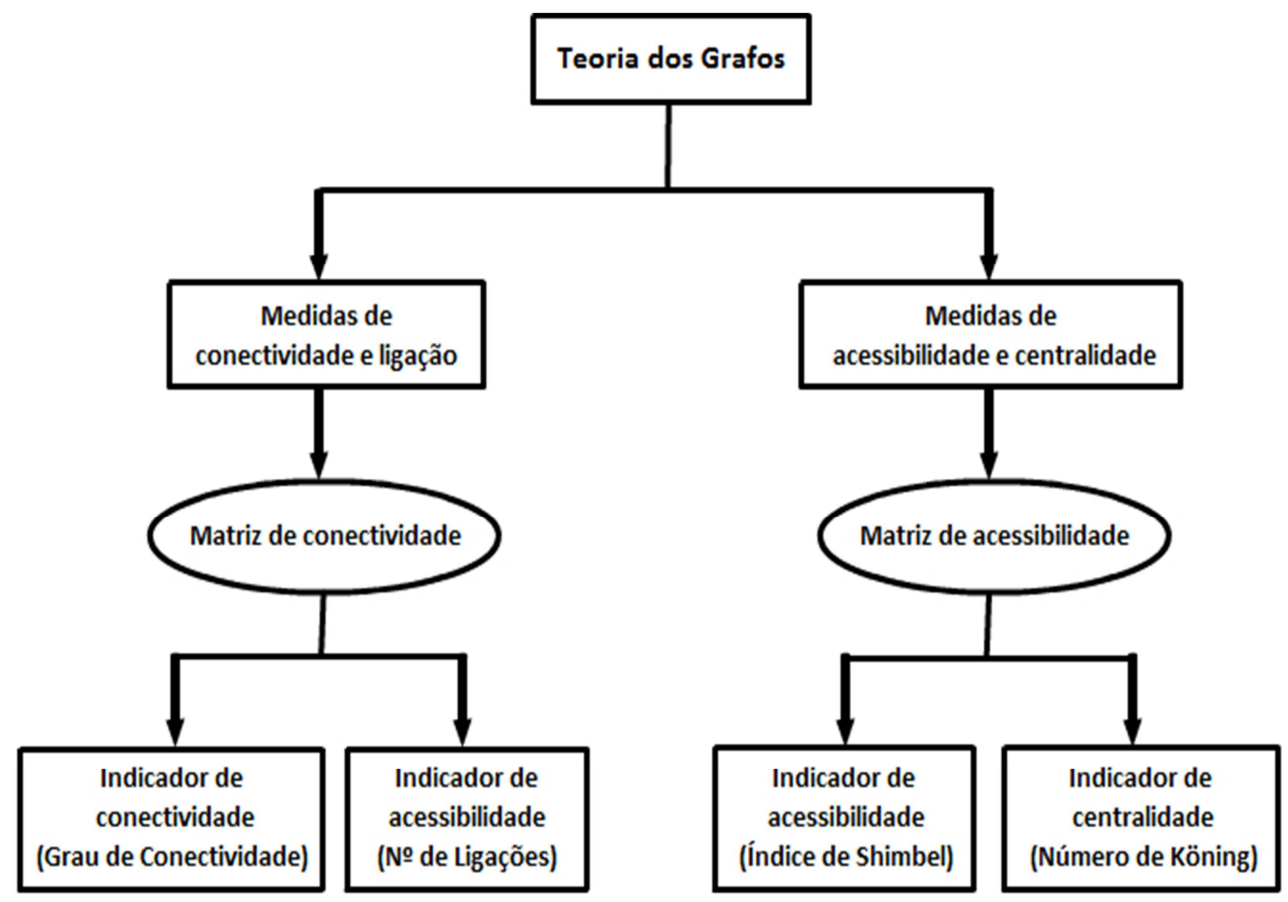

Figura 3 - Procedimentos para determinação dos indicadores de conectividade acessibilidade e centralidade. 
As medidas de conectividade e ligação permitem analisar a estrutura geral da rede, através do grau de conectividade (número total de arcos / número total de nós), definido por Shimbel (1953), e do número de ligações. Neste tipo de medidas, as ligações (arcos) são directas, ou seja são feitas somente entre dois nós (aldeias) da rede.

Elaborou-se uma rede topológica definida por nós e arcos, estabelecendo as ligações entre as aldeias (figuras $4 \mathrm{a}$ e b). Na área norte 11 aldeias pertencem à Guiné-Bissau e 13 ao Senegal, enquanto na leste 19 cabem à Guiné-Bissau e 10 à Guiné-Conacri. A partir da rede de ligações entre os nós, produziu-se a matriz de conectividade (tabela 1), da qual se obteve o número de ligações para cada nó, através do somatório de cada linha da matriz.

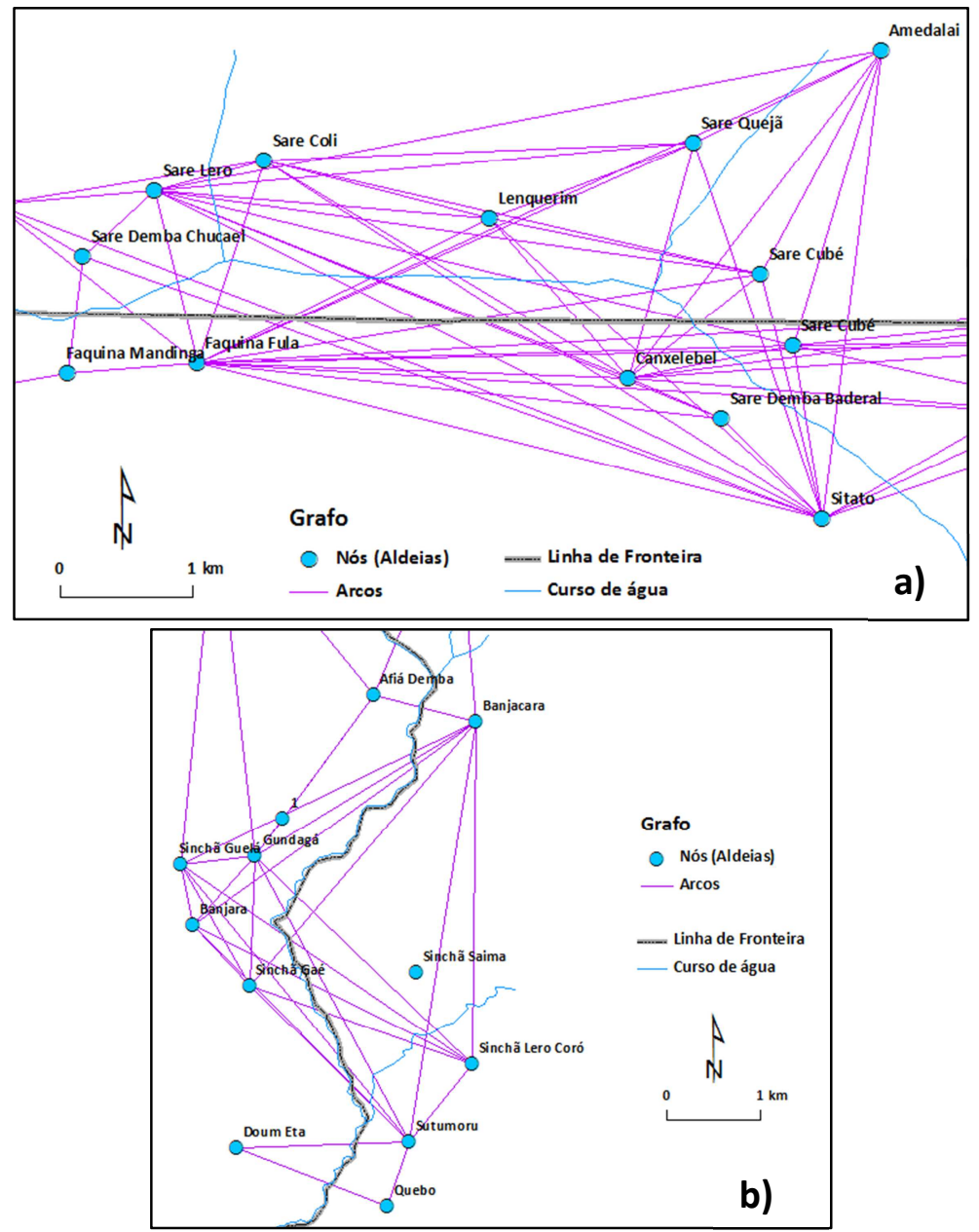

Figura 4 - Extractos dos grafos entre aldeias nas áreas de estudo da fronteira: a) norte com o Senegal; b) leste com a Guiné-Conacri.

A área da fronteira com o Senegal tem 72 arcos e 24 nós (tabela 1a), pelo que o grau de conectividade é de 3,0 e com a Guiné-Conacri dispõe de 93 arcos e 29 nós (tabela 1b), de 
que resulta um grau de conectividade de 3,2. Como em ambas as áreas o valor é superior a

1, podem ser consideradas redes completas e de forte conectividade, consequentemente bem estruturadas, o que pode ser um indicador do nível de desenvolvimento das regiões e da complexidade das relações espaciais.

Tabela 1 - Matrizes de conectividade nas áreas de estudo da fronteira da Guiné-Bissau com o Senegal e com a Guiné-Conacri.

a) Senegal

\begin{tabular}{|c|c|c|c|c|c|c|c|c|c|c|c|c|c|c|c|c|c|c|c|c|c|c|c|c|c|}
\hline & \begin{tabular}{|l|l|l|l|l|} 
\\
\end{tabular} & FManding & FFula & Canxelebel & sDBaderal & Subé_G & \begin{tabular}{|l|} 
Sitato \\
\end{tabular} & 6 & SDember & \begin{tabular}{|l|} 
Madina \\
\end{tabular} & Lenquebembè & SNDiaye & & Sconco & Sonco & $\theta$ & SOChucael & SLeros & olit & Lenquerim & SQueijä| & Scube_s & Amedalai & SSori & \\
\hline Jaljalito & & 1 & 0 & 0 & 0 & 0 & 0 & 0 & 0 & 0 & 0 & 0 & 0 & 0 & 0 & 0 & 0 & 0 & 0 & 0 & 0 & 0 & 0 & \begin{tabular}{l|l}
0 \\
\end{tabular} & \\
\hline Fandinga & 1 & & 1 & 0 & 0 & 0 & 0 & 0 & 0 & 0 & 0 & 0 & 0 & 0 & 0 & 0 & 1 & 0 & 0 & 0 & 0 & 0 & 0 & 0 & 3 \\
\hline FFula & 0 & 1 & & 1 & 1 & 1 & 1 & 1 & 0 & 1 & 0 & 0 & 0 & 0 & 0 & 1 & 1 & 1 & 1 & 1 & 1 & 1 & 1 & \begin{tabular}{|l|l|} 
\\
\end{tabular} & 16 \\
\hline Canxelebel & 0 & 0 & 1 & & 1 & 1 & 1 & 1 & 0 & 1 & 0 & 8 & 0 & 0 & 0 & 1 & 1 & 1 & 1 & 1 & 1 & 1 & 1 & \begin{tabular}{|l|l|} 
& \\
\end{tabular} & 15 \\
\hline SOBaderal & 0 & 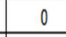 & 1 & 1 & & 1 & 1 & 1 & 0 & 1 & 0 & 0 & 0 & 0 & 0 & 1 & 1 & 1 & 1 & 1 & 1 & 1 & 1 & \begin{tabular}{|l|l|} 
\\
\end{tabular} & 15 \\
\hline Scubé_GB & 0 & 0 & 1 & 1 & 1 & & 1 & 1 & 0 & 1 & 0 & ( & 0 & 0 & 0 & 1 & 1 & 1 & 1 & 1 & 1 & 1 & 1 & 1 & 15 \\
\hline Sitito & 0 & 0 & 1 & 1 & 1 & 1 & & 1 & 0 & 1 & 0 & 0 & 0 & 0 & 0 & 1 & 1 & 1 & 1 & 1 & 1 & 1 & 1 & 1 & \\
\hline 6 & 0 & 0 & 1 & 1 & 1 & 1 & 1 & & 1 & 1 & 0 & 0 & 0 & 0 & 0 & 1 & 1 & 1 & 1 & 1 & 1 & 1 & 1 & \begin{tabular}{|l|l|} 
\\
\end{tabular} & 16 \\
\hline Soembel & 0 & 0 & 0 & 0 & 0 & 0 & 0 & 1 & & 0 & 0 & 0 & 0 & 0 & 0 & 0 & 0 & 0 & 0 & 0 & 0 & 0 & 0 & 0 & \\
\hline Madina & 0 & 0 & 1 & 1 & 1 & 1 & 1 & 1 & 0 & & 0 & 0 & 0 & 0 & 0 & 1 & 1 & 1 & 1 & 1 & 1 & 1 & 1 & \begin{tabular}{|l|l|} 
\\
\end{tabular} & 15 \\
\hline Lenquebembè & 0 & 0 & 0 & 0 & 0 & 0 & 0 & 0 & 0 & 0 & & 0 & 0 & 0 & 0 & 0 & 0 & 0 & 0 & 0 & 0 & 0 & 0 & 0 & \\
\hline SNDiaye & 0 & 0 & 0 & 0 & 0 & 0 & 0 & 0 & 0 & 0 & 0 & & 1 & 1 & 1 & 0 & 0 & 0 & 0 & 0 & 0 & 0 & 0 & \begin{tabular}{l|l} 
\\
\end{tabular} & \\
\hline 3 & 0 & 0 & 0 & 0 & 0 & 0 & 0 & 0 & 0 & 0 & 0 & 1 & & 1 & 1 & 0 & 0 & 0 & 0 & 0 & 0 & 0 & 0 & 0 & \\
\hline Sconco & 0 & 0 & 0 & 0 & 0 & 0 & 0 & 0 & 0 & 0 & 0 & 1 & 1 & & 1 & 0 & 0 & 0 & 0 & 0 & 0 & 0 & 0 & 0 & \\
\hline Sonco & 0 & 0 & 0 & 0 & 0 & 0 & 0 & 0 & 0 & 0 & 0 & 1 & \begin{tabular}{|l|} 
\\
\end{tabular} & 1 & & 1 & 0 & 0 & 0 & 0 & 0 & 0 & 0 & 0 & \\
\hline 7 & 0 & 0 & 1 & 1 & 1 & 1 & 1 & 1 & 0 & 1 & 0 & 0 & 0 & 0 & 1 & & 1 & \begin{tabular}{l|l} 
\\
\end{tabular} & 1 & 1 & 1 & 1 & 1 & \begin{tabular}{|l|l|} 
\\
\end{tabular} & 16 \\
\hline Sochucael & 0 & 1 & 1 & 1 & 1 & 1 & 1 & 1 & 0 & 1 & 0 & 0 & 0 & 0 & 0 & 1 & & \begin{tabular}{|l|} 
\\
\end{tabular} & 1 & 1 & 1 & 1 & 1 & \begin{tabular}{|l|l} 
\\
\end{tabular} & 16 \\
\hline Stero & 0 & 0 & 1 & 1 & 1 & 1 & 1 & 1 & 0 & 1 & 0 & 0 & 0 & 0 & 0 & 1 & 1 & & 1 & 1 & 1 & 1 & 1 & \begin{tabular}{|l|} 
\\
\end{tabular} & 15 \\
\hline Scoli & 0 & 0 & 1 & 1 & 1 & 1 & 1 & 1 & 0 & 1 & 0 & 0 & 0 & 0 & 0 & 1 & 1 & \begin{tabular}{l|l} 
\\
\end{tabular} & & 1 & 1 & 1 & 1 & \begin{tabular}{|l|l|} 
\\
\end{tabular} & 15 \\
\hline Lenquerim & 0 & 0 & 1 & 1 & 1 & 1 & 1 & 1 & 0 & 1 & 0 & 0 & 0 & 0 & 0 & 1 & 1 & 1 & 1 & & 1 & 1 & 1 & 1 & 15 \\
\hline SQuevijã & 0 & 0 & 1 & 1 & 1 & 1 & 1 & 1 & 0 & 1 & 0 & 0 & 0 & 0 & 0 & 1 & 1 & 1 & 1 & 1 & & 1 & 1 & \begin{tabular}{|l|l|} 
\\
\end{tabular} & 15 \\
\hline Scubés & 0 & 0 & 1 & 1 & 1 & 1 & 1 & 1 & 0 & 1 & 0 & 0 & 0 & 0 & 0 & 1 & 1 & 1 & 1 & 1 & 1 & & 1 & \begin{tabular}{|l|}
1 \\
\end{tabular} & \\
\hline Amedalai & 0 & 0 & 1 & 1 & 1 & 1 & 1 & 1 & 0 & 1 & 0 & 0 & 0 & 0 & 0 & 1 & 1 & 1 & 1 & 1 & 1 & 1 & & \begin{tabular}{|l|}
1 \\
\end{tabular} & 15 \\
\hline SSori & 0 & 0 & 1 & 1 & 1 & 1 & 1 & 1 & 0 & 1 & 0 & 0 & 0 & 0 & 0 & 1 & 1 & 1 & 1 & 1 & 1 & 1 & 1 & & 1 \\
\hline$\sum$ & 1 & 3 & 16 & 15 & 15 & 15 & 15 & 16 & 1 & 15 & 0 & 3 & 3 & 3 & 4 & 16 & 16 & \begin{tabular}{|l|}
15 \\
\end{tabular} & 15 & 15 & 15 & 15 & 15 & \begin{tabular}{|l|}
15 \\
\end{tabular} & \\
\hline
\end{tabular}

b) Guiné-Conacri

\begin{tabular}{|c|c|c|c|c|c|c|c|c|c|c|c|c|c|c|c|c|c|c|c|c|c|c|c|c|c|c|c|c|c|}
\hline & DEtals & Gaél] & anjararals & Gueval][ & undoga & & ADembe & Sampa] & Quinse & SBollama & 19a|Amedalas & ai Concôd & di Buruntuma & a|clessel| & & Catabál & Tenderio & & Donnejo & Queboo & 0 & \begin{tabular}{|c|} 
CSêuro \\
\end{tabular} & & Candical & Sutälaz & enjectro & |Ssaima & Sutumoru & \\
\hline Deta & & 0 & 0 & 0 & 0 & 0 & 0 & 0 & 0 & 0 & 0 & 0 & 0 & 0 & \begin{tabular}{|l|}
0 \\
\end{tabular} & 0 & 0 & \begin{tabular}{|l|} 
\\
\end{tabular} & 0 & 1 & 0 & 0 & 0 & 0 & 0 & 0 & 0 & 1 & \\
\hline SGáé & 0 & & 1 & 1 & 1 & 0 & 0 & 0 & 0 & 0 & 0 & 0 & 0 & 0 & $\begin{array}{ll} \\
\end{array}$ & 0 & 0 & \begin{tabular}{|l|} 
\\
\end{tabular} & 0 & 0 & 1 & 0 & $\begin{array}{ll} \\
\end{array}$ & 0 & 0 & 1 & 0 & 1 & 0 \\
\hline Banjara & 0 & 1 & & 1 & 1 & 80 & 0 & 0 & 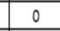 & 0 & 0 & 0 & 0 & 0 & 0 & 0 & 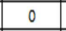 & \begin{tabular}{|l|}
0 \\
\end{tabular} & 0 & 0 & 1 & 0 & \begin{tabular}{l|l|}
0 \\
\end{tabular} & 0 & 0 & 1 & 0 & 1 & \\
\hline SGuelá & 0 & 1 & 1 & & 1 & 0 & 0 & 1 & 0 & 0 & 0 & 0 & 0 & 0 & 0 & 0 & 0 & \begin{tabular}{|l|}
0 \\
\end{tabular} & 0 & 0 & 1 & 0 & \begin{tabular}{|l|}
0 \\
\end{tabular} & 0 & 0 & 1 & 0 & 1 & 0 \\
\hline Gundagá & 0 & 1 & 1 & 1 & & \begin{tabular}{|l|}
1 \\
\end{tabular} & 1 & 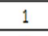 & 0 & 0 & 0 & 0 & 0 & 0 & 0 & 0 & 0 & 10 & 0 & 0 & 1 & 0 & 0 & 0 & 0 & 1 & 0 & 1 & \\
\hline 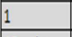 & 0 & 0 & 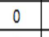 & 0 & 1 & & 4 & 0 & 0 & 0 & 0 & 7 & 0 & & 0 & 8 & 0 & 7 & 0 & 0 & 0 & 0 & 2 & 0 & 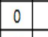 & & 0 & 0 & \\
\hline ADemba & 0 & & 0 & 0 & 1 & \begin{tabular}{|l|} 
\\
\end{tabular} & & 1 & 0 & 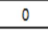 & 0 & 0 & 0 & 0 & 0 & 0 & 0 & \begin{tabular}{|l|}
0 \\
\end{tabular} & 0 & 0 & 0 & 1 & \begin{tabular}{|l|}
0 \\
\end{tabular} & 0 & 0 & 1 & 0 & 0 & \\
\hline Sampoje & 0 & 0 & 0 & 1 & 1 & 0 & 1 & & 1 & 4 & 0 & 4 & 0 & & 0 & 0 & 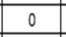 & \begin{tabular}{|l|}
0 \\
\end{tabular} & 0 & 0 & 0 & 1 & \begin{tabular}{|l|}
0 \\
\end{tabular} & 0 & 0 & 0 & 0 & 0 & \\
\hline Squinsé & 0 & 0 & 0 & 0 & 0 & 0 & 0 & 1 & & 1 & 0 & 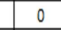 & 0 & 0 & 0 & 0 & 0 & \begin{tabular}{|l|}
0 \\
\end{tabular} & 0 & 0 & 0 & 1 & 0 & 0 & 0 & & 0 & 0 & 0 \\
\hline S80lama & 0 & 0 & 8 & 0 & 0 & 0 & 8 & 1 & 1 & & 1 & 4 & 1 & 1 & \begin{tabular}{|l|}
1 \\
\end{tabular} & 1 & 0 & \begin{tabular}{|l|} 
\\
\end{tabular} & 0 & 0 & 0 & 1 & $\begin{array}{ll} \\
\end{array}$ & 1 & \begin{tabular}{|l|} 
\\
\end{tabular} & 0 & 0 & 0 & \\
\hline Amedalai & 0 & 0 & 0 & 0 & 0 & 0 & 0 & 0 & 0 & 1 & & 1 & & & 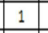 & 1 & & \begin{tabular}{|l|}
0 \\
\end{tabular} & 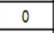 & 0 & 0 & 1 & & 1 & & & & 0 & \\
\hline Concôodi & 0 & 0 & 0 & 0 & 0 & 0 & 0 & 0 & 0 & 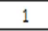 & 1 & & 1 & 1 & \begin{tabular}{l|l}
1 \\
\end{tabular} & 1 & 0 & 0 & 0 & 0 & 0 & 1 & \begin{tabular}{|l|}
0 \\
\end{tabular} & 1 & \begin{tabular}{|l|}
1 \\
\end{tabular} & 0 & 0 & 0 & \\
\hline Burruntuma & 0 & 0 & 0 & 0 & 0 & 0 & 0 & 0 & 0 & 1 & 1 & 1 & & 1 & \begin{tabular}{|l|}
1 \\
\end{tabular} & 1 & 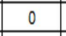 & \begin{tabular}{|l|}
0 \\
\end{tabular} & 0 & 0 & 0 & 1 & \begin{tabular}{|l|}
1 \\
\end{tabular} & 1 & \begin{tabular}{|l|}
1 \\
\end{tabular} & 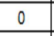 & 0 & 0 & \\
\hline Clessel & 0 & 0 & 0 & 0 & 0 & 0 & 0 & 0 & 0 & 1 & 1 & 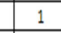 & 1 & & \begin{tabular}{|l|}
1 \\
\end{tabular} & 1 & 0 & \begin{tabular}{|l|}
0 \\
\end{tabular} & 0 & 0 & 0 & 0 & \begin{tabular}{|l|}
0 \\
\end{tabular} & 1 & \begin{tabular}{|l|}
1 \\
\end{tabular} & 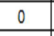 & 0 & 0 & \\
\hline SSori & 0 & 0 & 0 & 0 & 0 & 0 & 0 & 0 & 0 & 1 & 1 & 1 & 1 & 1 & & 1 & 0 & \begin{tabular}{|l|}
0 \\
\end{tabular} & 0 & 0 & 0 & 0 & \begin{tabular}{|l|}
0 \\
\end{tabular} & 1 & \begin{tabular}{|l|}
1 \\
\end{tabular} & 0 & 0 & 0 & \\
\hline Cotabá & 0 & 0 & 0 & 8 & 0 & 0 & 0 & 0 & 0 & 1 & 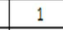 & 1 & 1 & 1 & 1 & & 1 & 0 & & & & & 0 & & 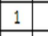 & & & 0 & \\
\hline Tendeiro & 0 & 0 & 0 & 0 & 0 & 0 & 0 & 0 & 0 & 0 & 0 & 0 & c & 0 & 0 & 1 & & 1 & 1 & 0 & 0 & 0 & \begin{tabular}{l|}
0 \\
\end{tabular} & 0 & 1 & 0 & 0 & 0 & 0 \\
\hline & 0 & 0 & 0 & 0 & 0 & 0 & 0 & 0 & 0 & 0 & & 0 & & 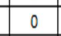 & 0 & 0 & 1 & & 1 & 0 & 0 & 0 & $\begin{array}{ll} \\
\end{array}$ & 0 & 0 & & 0 & 0 & 0 \\
\hline Doanejo & 0 & 0 & 0 & 0 & 0 & 0 & 0 & 0 & 0 & 0 & 0 & 0 & 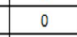 & 0 & \begin{tabular}{l|}
0 \\
\end{tabular} & 0 & 1 & 1 & & 0 & 0 & 0 & \begin{tabular}{|l|}
0 \\
\end{tabular} & 0 & 0 & 0 & 0 & 0 & 0 \\
\hline Quebo & 1 & 0 & 0 & 0 & 0 & 0 & 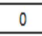 & 0 & 0 & 0 & 0 & 0 & 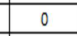 & & \begin{tabular}{|l|}
0 \\
\end{tabular} & 0 & 0 & \begin{tabular}{|l|} 
\\
\end{tabular} & 0 & & 0 & 0 & $\begin{array}{ll} \\
\end{array}$ & 0 & 0 & 0 & 0 & 1 & \\
\hline scoró & 0 & 1 & 1 & 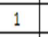 & 1 & 0 & 0 & 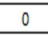 & 0 & 0 & 0 & 0 & 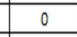 & 0 & \begin{tabular}{|l|}
0 \\
\end{tabular} & 0 & 0 & 0 & 0 & \begin{tabular}{|l|}
0 \\
\end{tabular} & & 0 & \begin{tabular}{|l|}
0 \\
\end{tabular} & 0 & 0 & 1 & 0 & 1 & \\
\hline CSêro & 0 & & 0 & 0 & 0 & 0 & 1 & 1 & 1 & 1 & 1 & 1 & 1 & c & 0 & 0 & 0 & \begin{tabular}{|l|} 
\\
\end{tabular} & 0 & 0 & 0 & & 1 & 1 & 0 & 1 & 0 & 0 & \\
\hline & 0 & 0 & 0 & 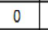 & 0 & 0 & 0 & 0 & 0 & 0 & 1 & 0 & & 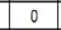 & 0 & 0 & & 0 & & 0 & 0 & 1 & & 1 & 0 & & & & \\
\hline Candiça & 0 & 0 & 0 & 0 & 0 & 0 & 0 & 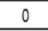 & 0 & 1 & 1 & 1 & 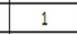 & 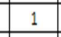 & \begin{tabular}{|l|}
1 \\
\end{tabular} & 1 & 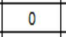 & \begin{tabular}{|l|}
0 \\
\end{tabular} & 0 & 0 & 0 & 1 & \begin{tabular}{|l|}
1 \\
\end{tabular} & & 1 & 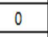 & 0 & 0 & 0 \\
\hline Sutát & 0 & 0 & 0 & 0 & 0 & 0 & 0 & 0 & 0 & 1 & 1 & 1 & 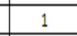 & 1 & 1 & 1 & - & 0 & 0 & 0 & 0 & 0 & 0 & 1 & & 0 & 0 & 0 & \\
\hline Banjacara & 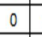 & & 1 & 1 & 1 & 0 & 1 & 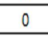 & 0 & 0 & 0 & 0 & c & 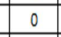 & \begin{tabular}{|l|}
0 \\
\end{tabular} & 0 & 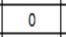 & 0 & 0 & 0 & 1 & \begin{tabular}{|l|}
1 \\
\end{tabular} & \begin{tabular}{|l|} 
\\
\end{tabular} & 0 & & & 0 & 1 & 0 \\
\hline SSSaima & 0 & 0 & 0 & 0 & 0 & 0 & 8 & 0 & 0 & 0 & 0 & 0 & 0 & 0 & 0 & 0 & 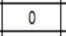 & 0 & 0 & 0 & 0 & 0 & 0 & 0 & 0 & 0 & & 0 & 0 \\
\hline Sutumoru & 1 & & 1 & 1 & 1 & 0 & 0 & 0 & o & 0 & t & 0 & & & 0 & & & & & & & & 0 & 0 & 0 & & 0 & & 0 \\
\hline 3 & 0 & 0 & 0 & 0 & 0 & 0 & 0 & 0 & 0 & 1 & 1 & 1 & & 1 & 1 & 1 & 0 & 0 & 0 & 0 & 0 & 0 & \begin{tabular}{|l|}
1 \\
\end{tabular} & 0 & \begin{tabular}{|l|}
1 \\
\end{tabular} & 0 & 0 & 0 & \\
\hline & 2 & 6 & 6 & 7 & 9 & 2 & 7 & 6 & 3 & 12 & 11 & 10 & 11 & 9 & 9 & \begin{tabular}{|l|}
10 \\
\end{tabular} & 4 & & 2 & 2 & 6 & 10 & \begin{tabular}{|l|l|}
5 \\
\end{tabular} & 10 & 10 & 8 & 0 & 8 & 9 \\
\hline
\end{tabular}


Na fronteira com o Senegal, 15 das 24 aldeias têm mais de 15 ligações directas (figura 5a), enquanto na fronteira com a Guiné-Conacri, 19 das 29 têm entre 6 e 10 ligações directas e apenas uma aldeia dispõe de 12 , correspondendo ao número mais elevado (figura $5 b$ ). No conjunto estes valores são inferiores aos da área de estudo da fronteira norte com o Senegal.

$\mathrm{Na}$ área situada a norte, uma estrada principal e outros 17 eixos viários atravessam a fronteira. No Senegal existe uma estrada secundária paralela à linha de fronteira, em cerca de metade da extensão da área de estudo, que estabelece a ligação entre as aldeias mais importantes (figura 5a).
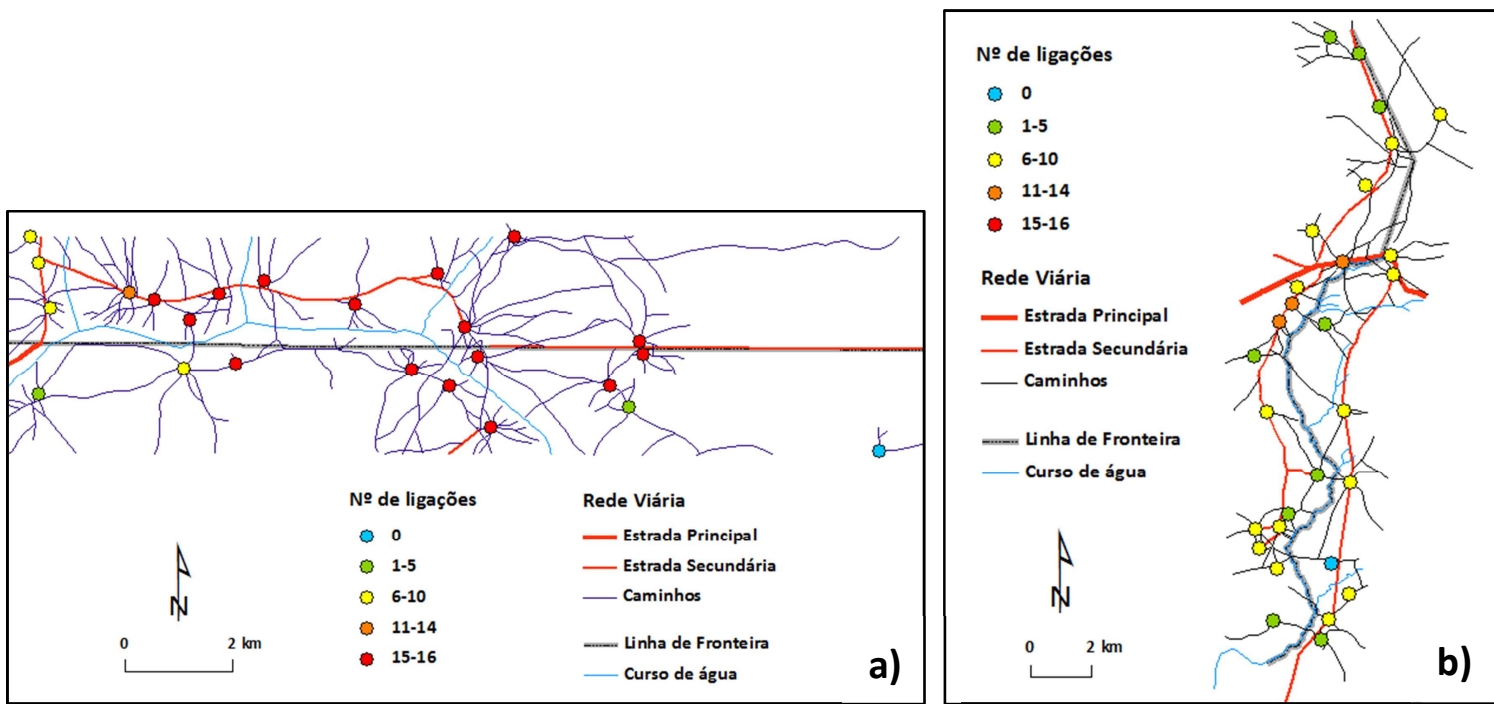

Figura 5 - Ligações entre as aldeias nas áreas de estudo da fronteira com: a) o Senegal; b) a Guiné-Conacri.

Em relação à área leste, uma estrada principal e 14 caminhos cruzam a fronteira com a Guiné-Conacri (figura 5b), país onde se encontra uma estrada secundária ao longo de cerca de dois terços da fronteira. Na Guiné-Bissau, existe uma estrada secundária paralela a quase toda a extensão da linha de fronteira.

As medidas de acessibilidade e centralidade permitem fazer uma análise interna da rede. Ao contrário das medidas de conectividade e ligação, estes indicadores apontam o número de caminhos possíveis de um nó a qualquer outro da rede, ou seja estabelecem as ligações indirectas entre os nós (aldeias). Para cada uma das áreas construiu-se uma matriz de acessibilidade (tabela 2). 
Tabela 2 - Matrizes de acessibilidade nas áreas de estudo da fronteira da Guiné-Bissau com o Senegal e com a Guiné-Conacri.

a) Senegal

\begin{tabular}{|c|c|c|c|c|c|c|c|c|c|c|c|c|c|c|c|c|c|c|c|c|c|c|c|c|c|c|}
\hline & 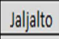 & FMandinga & FFula & Canxelebe & SDBadera & Scubé_GB & Sitato & 6 & SDembel & Madina & Lenquebembè & SNDiaye & 3 & SConco & Sonco & 4 & SDChucael & Stero & SColit & Lenquerim & SQueijẫ & â Scubé_S & s Amedalai & ai SSori & is & NK \\
\hline Jaljalto & & 1 & 2 & 3 & 4 & 5 & 5 & 5 & 6 & 4 & 0 & 5 & 5 & 5 & 4 & 3 & 2 & 3 & 3 & 3 & 3 & 4 & 4 & 5 & 84 & 6 \\
\hline FMandinga & 1 & & 1 & 2 & 3 & 4 & 4 & 4 & 5 & 3 & 0 & 4 & 4 & 4 & 3 & 2 & 1 & 2 & 2 & 2 & 2 & 3 & 3 & 4 & 63 & 5 \\
\hline FFula & 2 & 1 & & 1 & 2 & 3 & 3 & 3 & 4 & 2 & 0 & 5 & 5 & 5 & 4 & 3 & 2 & 3 & 1 & 1 & 1 & 2 & 2 & 3 & 58 & 5 \\
\hline Canxelebel & 3 & 2 & 1 & & 1 & 1 & 2 & 2 & 3 & 1 & 0 & 6 & 6 & 6 & 5 & 4 & 3 & 1 & 1 & 2 & 2 & 1 & 2 & 2 & 57 & 6 \\
\hline SDBaderal & 4 & 3 & 2 & 1 & & 1 & 1 & 1 & 2 & 1 & 0 & 7 & 7 & 7 & 6 & 5 & 4 & 2 & 2 & 2 & 2 & 2 & 2 & 1 & 65 & 7 \\
\hline Scubé_GB & 5 & 4 & 3 & 1 & 1 & & 1 & 1 & 2 & 1 & 0 & 7 & 7 & 7 & 6 & 5 & 4 & 2 & 2 & 2 & 2 & 1 & 2 & 1 & 67 & 7 \\
\hline Sitato & 5 & 4 & 3 & 2 & 1 & 1 & & 1 & 2 & 1 & 0 & 8 & 8 & 8 & 7 & 6 & 5 & 6 & 3 & 3 & 2 & 1 & 2 & 1 & 80 & 8 \\
\hline 6 & 5 & 4 & 3 & 2 & 1 & 1 & 1 & & 1 & 1 & 0 & 9 & 9 & 9 & 8 & 7 & 6 & 4 & 4 & 2 & 2 & 1 & 2 & 1 & 83 & 9 \\
\hline SDembel & 6 & 5 & 4 & 3 & 2 & 2 & 2 & 1 & & 2 & 0 & 5 & 5 & 5 & 4 & 3 & 3 & 3 & 3 & 3 & 3 & 2 & 3 & 2 & 71 & 6 \\
\hline Madina & 4 & 3 & 2 & 1 & 1 & 1 & 1 & 1 & 2 & & 0 & 4 & 4 & 4 & 3 & 2 & 2 & 2 & 2 & 2 & 3 & 2 & 2 & 1 & 49 & 4 \\
\hline Lenquebembè & 0 & 0 & 0 & 0 & 0 & 0 & 0 & 0 & 0 & 0 & & 0 & 0 & 0 & 0 & 0 & 0 & 0 & 0 & 0 & 0 & 0 & 0 & 0 & 0 & 0 \\
\hline SNDiaye & 5 & 4 & 5 & 6 & 7 & 7 & 8 & 9 & 5 & 4 & 0 & & 1 & 2 & 1 & 2 & 3 & 3 & 3 & 3 & 3 & 3 & 3 & 4 & 91 & 9 \\
\hline 3 & 5 & 4 & 5 & 6 & 7 & 7 & 8 & 9 & 5 & 4 & 0 & 1 & & 1 & 1 & 2 & 3 & 3 & 3 & 3 & 3 & 3 & 3 & 4 & 90 & 9 \\
\hline SConco & 5 & 4 & 5 & 6 & 7 & 7 & 8 & 9 & 5 & 4 & 0 & 2 & 1 & & 1 & 2 & 3 & 3 & 3 & 3 & 3 & 3 & 3 & 4 & 91 & 9 \\
\hline Sonco & 4 & 3 & 4 & 5 & 6 & 6 & 7 & 8 & 4 & 3 & 0 & 1 & 1 & 1 & & 1 & 2 & 2 & 2 & 2 & 2 & 2 & 2 & 2 & 70 & 8 \\
\hline 4 & 3 & 2 & 3 & 4 & 5 & 5 & 6 & 7 & 3 & 2 & 0 & 2 & 2 & 2 & 1 & & 1 & 1 & 1 & 1 & 1 & 1 & 1 & 2 & 56 & 7 \\
\hline SOChucael & 2 & 1 & 2 & 3 & 4 & 4 & 5 & 6 & 3 & 2 & 0 & 3 & 3 & 3 & 2 & 1 & & 1 & 1 & 1 & 1 & 1 & 1 & 2 & 52 & 6 \\
\hline SLero & 3 & 2 & 3 & 1 & 2 & 2 & 6 & 4 & 3 & 2 & 0 & 3 & 3 & 3 & 2 & 1 & 1 & & 1 & 1 & 1 & 1 & 1 & 2 & 48 & 6 \\
\hline SColi & 3 & 2 & 1 & 1 & 2 & 2 & 3 & 4 & 3 & 2 & 0 & 3 & 3 & 3 & 2 & 1 & 1 & 1 & & 1 & 1 & 1 & 1 & 2 & 43 & 4 \\
\hline Lenquerim & 3 & 2 & 1 & 2 & 2 & 2 & 3 & 2 & 3 & 2 & 0 & 3 & 3 & 3 & 2 & 1 & 1 & 1 & 1 & & 1 & 1 & 1 & 2 & 42 & 3 \\
\hline SQueijä & 3 & 2 & 1 & 2 & 2 & 2 & 2 & 2 & 3 & 3 & 0 & 3 & 3 & 3 & 2 & 1 & 1 & 1 & 1 & 1 & & 1 & 1 & 2 & 42 & 3 \\
\hline Scubés $\mathrm{S}$ & 4 & 3 & 2 & 1 & 2 & 1 & 1 & 1 & 2 & 2 & 0 & 3 & 3 & 3 & 2 & 1 & 1 & 1 & 1 & 1 & 1 & & 1 & 1 & 38 & 4 \\
\hline Amedalai & 4 & 3 & 2 & 2 & 2 & 2 & 2 & 2 & 3 & 2 & 0 & 3 & 3 & 3 & 2 & 1 & 1 & 1 & 1 & 1 & 1 & 1 & & 1 & 43 & 4 \\
\hline SSori & 5 & 4 & 3 & 2 & 1 & 1 & 1 & 1 & 2 & 1 & 0 & 4 & 4 & 4 & 2 & 2 & 2 & 2 & 2 & 2 & 2 & 1 & 1 & & 49 & 5 \\
\hline IS & 84 & 63 & 58 & 57 & 65 & 67 & 80 & 83 & 71 & 49 & 0 & 91 & 90 & 91 & 70 & 56 & 52 & 48 & 43 & 42 & 42 & 38 & 43 & 49 & & \\
\hline NK & 6 & 5 & 5 & 6 & 7 & 7 & 8 & 9 & 6 & 4 & 0 & 9 & 9 & 9 & 8 & 7 & 6 & 6 & 4 & 3 & 3 & 4 & 4 & 5 & & \\
\hline
\end{tabular}

\section{b) Guiné-Conacri}

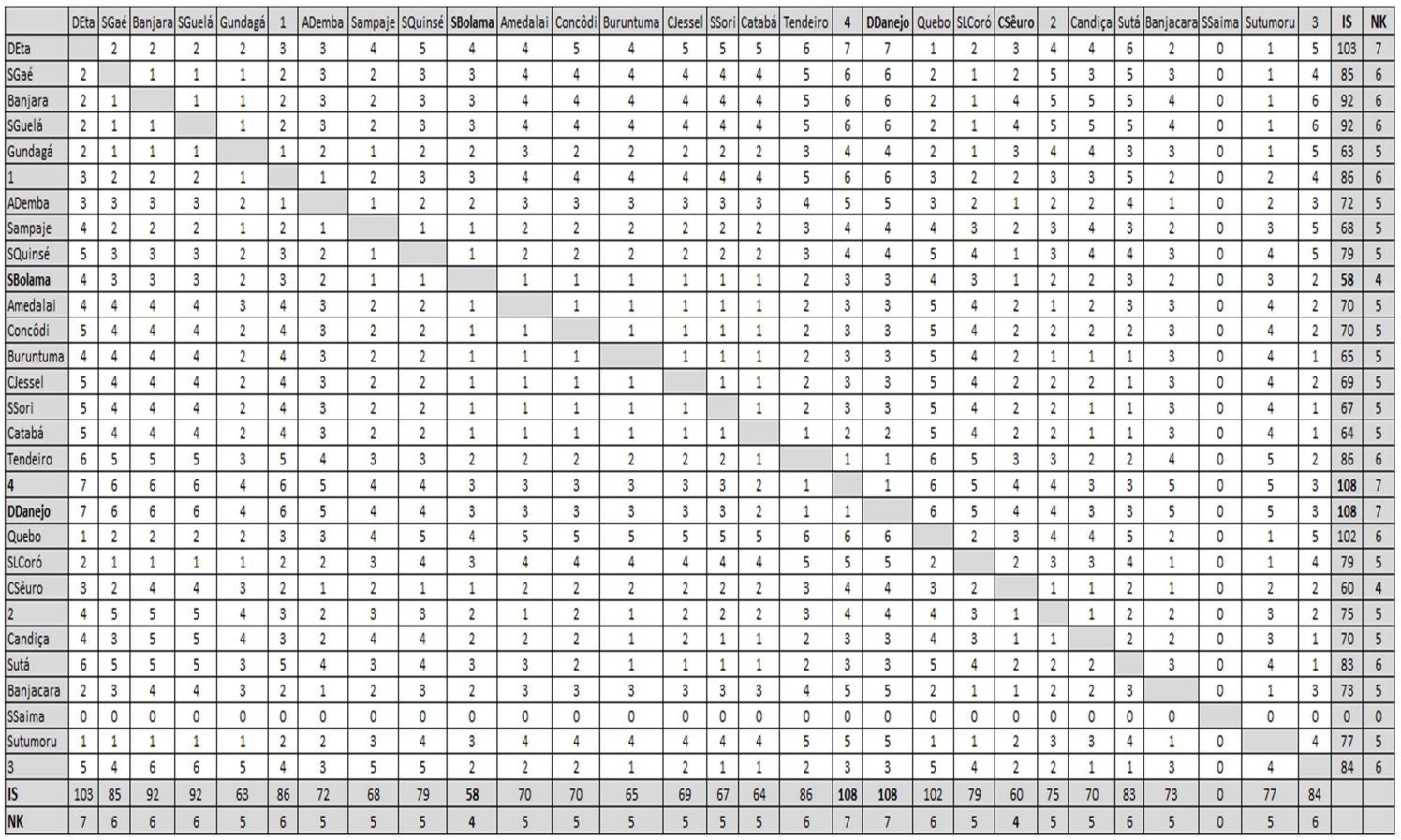


A partir da matriz obteve-se o Índice de Shimbel (IS), que corresponde ao somatório em linha da matriz das distâncias topológicas, e o Número de Köning (NK), que equivale ao valor máximo de cada linha. De ambas as colunas se retira o valor mínimo para obter, respectivamente, a aldeia com maior acessibilidade e centralidade. Num determinado espaço geográfico a aldeia mais acessível é a que tiver o menor valor de IS e a mais central a que tiver menor valor de NK.

A matriz de acessibilidade para a área de estudo do Senegal (tabela 2a) mostra que o valor mais baixo para o IS é de 38 e para o NK de 3. Estes valores significam, respectivamente, que a aldeia mais acessível é Sare Cubé (figura 6a) e as mais centrais são Lenquerim e Sare Quejã (figura 6b), todas localizadas no Senegal. Pode-se também observar que o IS com maior valor é 91 referente a Sare N'Diaye e Sare Conco, que correspondem às aldeias menos acessíveis, também situadas no Senegal (figura 6a).
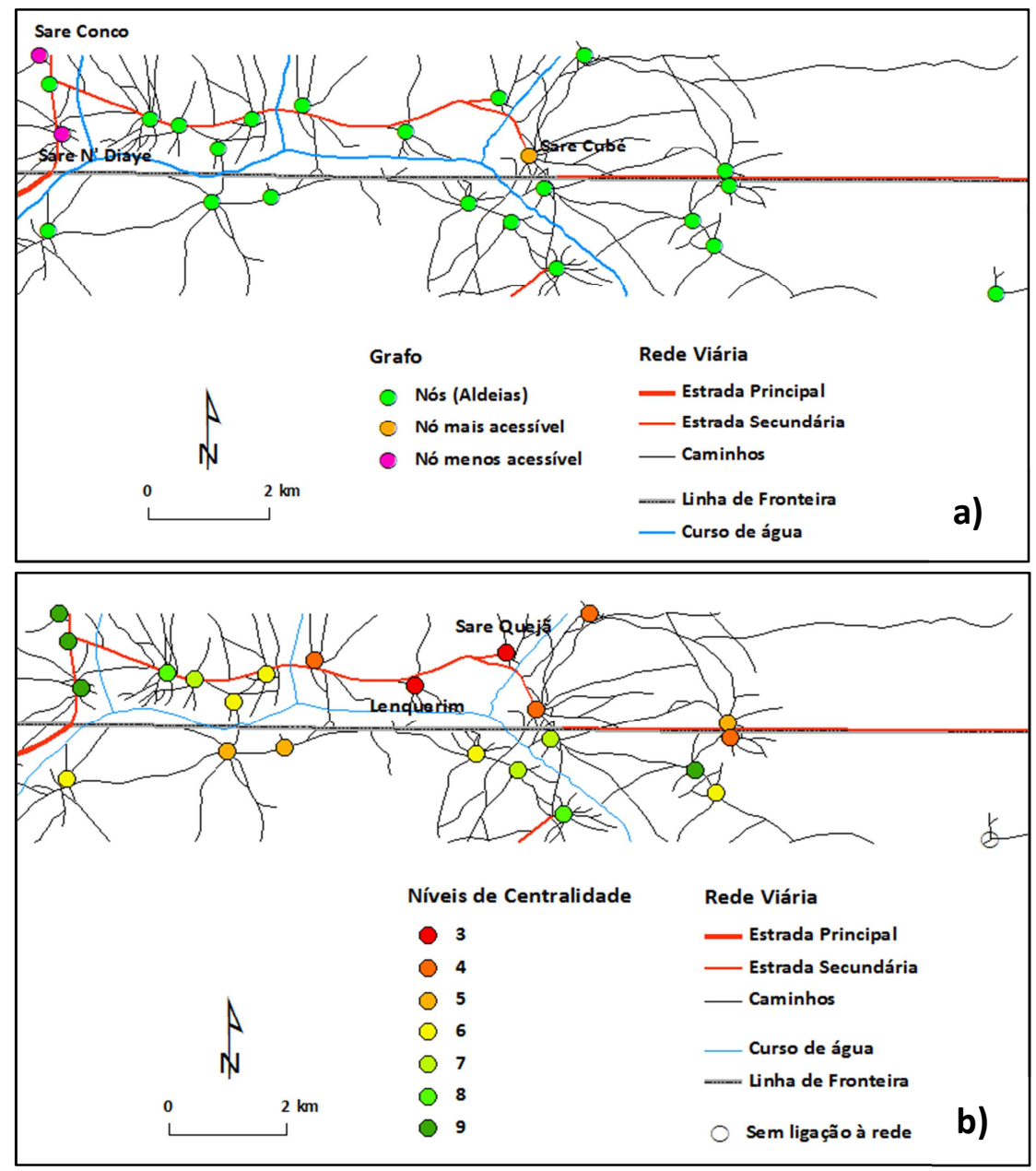

Figura 6 - Acessibilidade (a) e centralidade (b) entre as aldeias na área de estudo da fronteira com o Senegal. 
Em síntese, verifica-se que a aldeia mais acessível, a menos acessível e as mais centrais se encontram no território do Senegal, bem como três das quatro menos centrais. A acessibilidade e a centralidade são decrescentes para a periferia da área de estudo, sem qualquer relação com a linha de fronteira (figuras $6 a$ e b).

Relativamente à matriz de acessibilidade para a área de estudo da fronteira com a GuinéConacri (tabela 2 b) verifica-se que o valor mais baixo de NK é 4 e de IS é 58 , o que significa que Cambe Sêuro (Guiné-Conacri) e Sinchã Bolama (Guiné-Bissau) são as aldeias mais centrais, sendo esta última também a mais acessível. O valor mais elevado de IS é de 108, o que equivale às aldeias menos acessíveis da região de Demba Danejo (Guiné-Bissau).

Em resumo, tanto a aldeia mais acessível como as menos acessíveis se encontram no território da Guiné-Bissau. As duas mais centrais distribuem-se pelos dois países, cabendo as três menos centrais à Guiné-Bissau (figuras 7a e b).
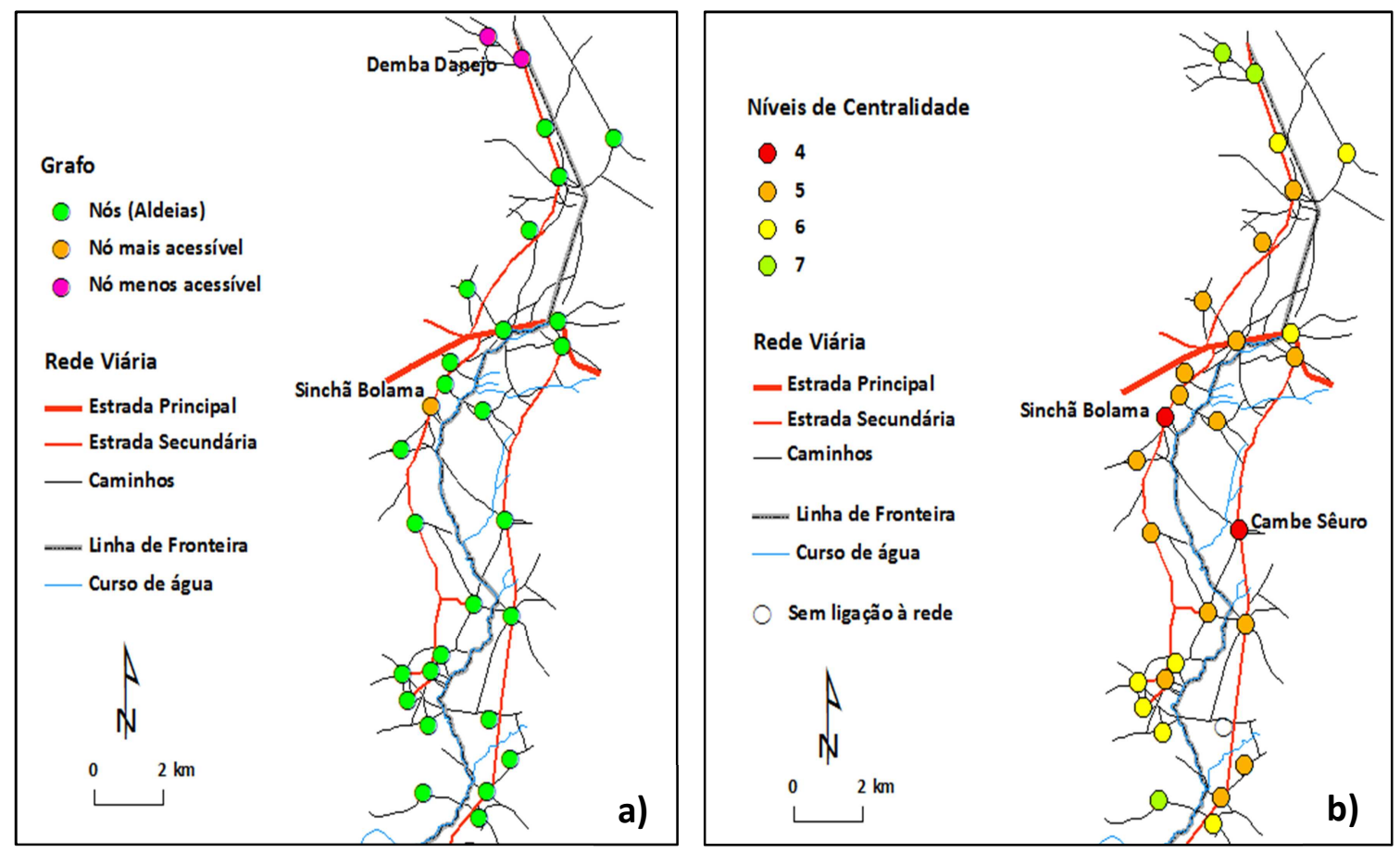

Figura 7 - Acessibilidade (a) e centralidade (b) entre as aldeias na área de estudo da fronteira com a Guiné-Conacri.

Analisando em conjunto as duas áreas é de referir que no espaço geográfico da fronteira com o Senegal tanto a aldeia mais acessível como a mais central se localizam no Senegal e, em contrapartida, na fronteira com a Guiné-Conacri encontram-se repartidas por ambos os 
países vizinhos. Estes aspectos sugerem um maior desenvolvimento da rede viária do Senegal em detrimento da Guiné-Bissau, na área de estudo norte, e da Guiné-Bissau em relação à Guiné-Conacri, na leste. Este facto é igualmente corroborado pelo número de aldeias existentes em cada país, como já foi referido.

\subsection{Análise do coberto do solo}

$\mathrm{Na}$ elaboração do mapa de coberto do solo foi definida uma legenda com seis classes: floresta aberta, savana arbórea, bolanha, ardido, água e solo nu. Este mapa foi obtido aplicando um método de classificação supervisada de máxima verosimilhança, sendo a precisão global resultante de $84.5 \%$ (Vasconcelos et al., 2014).

$\mathrm{Na}$ área norte (figura 8a) as manchas de coberto do solo mostram continuidade entre a Guiné-Bissau e o Senegal. A savana arbórea é o tipo de coberto predominante que ocupa cerca de $81 \%$ da superfície na Guiné-Bissau e $72 \%$ no Senegal (figuras 9a e b).
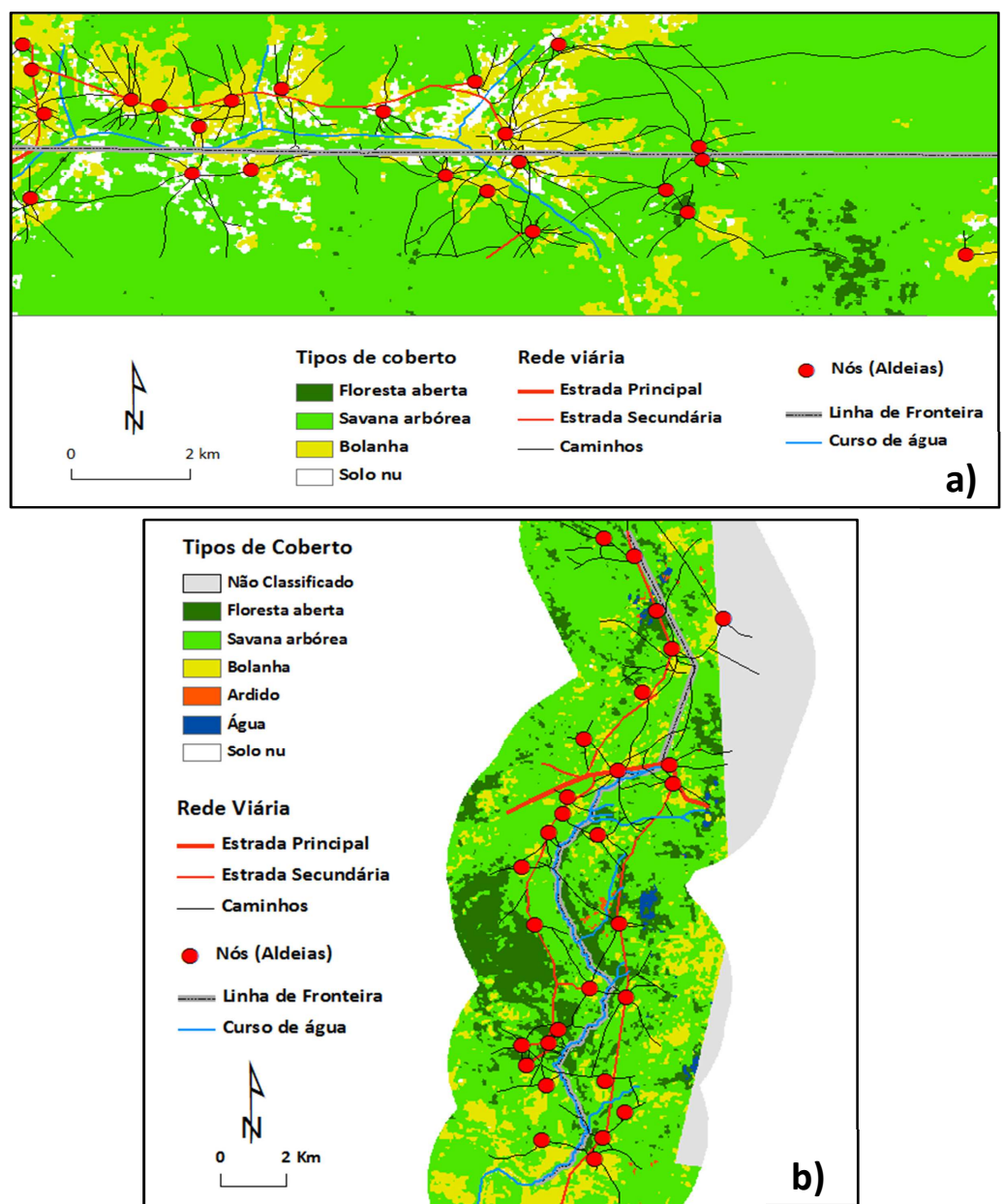

Figura 8 - Coberto do solo nas áreas da fronteira com: a) o Senegal; b) a Guiné-Conacri. 
As áreas de rizicultura (bolanhas) cobrem cerca de $11 \%$ e $21 \%$ da superfície, respectivamente na Guiné-Bissau e no Senegal (figuras 9a e b). Em ambos os países ocupam a maioria dos fundos de vales, na proximidade dos quais se localizam preferencialmente as povoações e se verifica um adensamento da rede viária. A maior área de bolanhas que se observa no Senegal deve-se à existência de um vale mais extenso e amplo, com condições de drenagem adequadas a culturas alagadas.
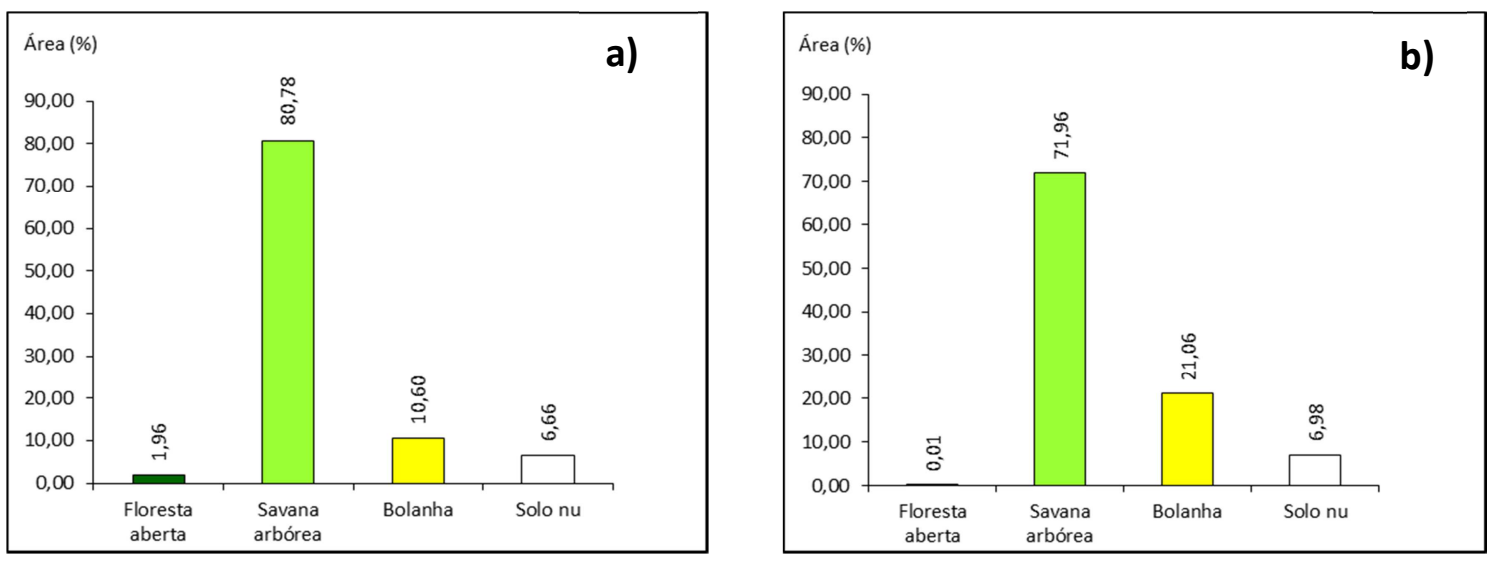

Figura 9 - Superfície ocupada pelos tipos de coberto do solo na área de estudo da fronteira norte: a) Guiné-Bissau; b) Senegal.

$\mathrm{Na}$ área leste na fronteira com a Guiné-Conacri, praticamente só a savana arbórea tem continuidade entre os dois países (figura 8 b), ocupando $54,5 \%$ e $69,6 \%$ respectivamente na Guiné-Conacri e na Guiné-Bissau (figuras 10a e b).
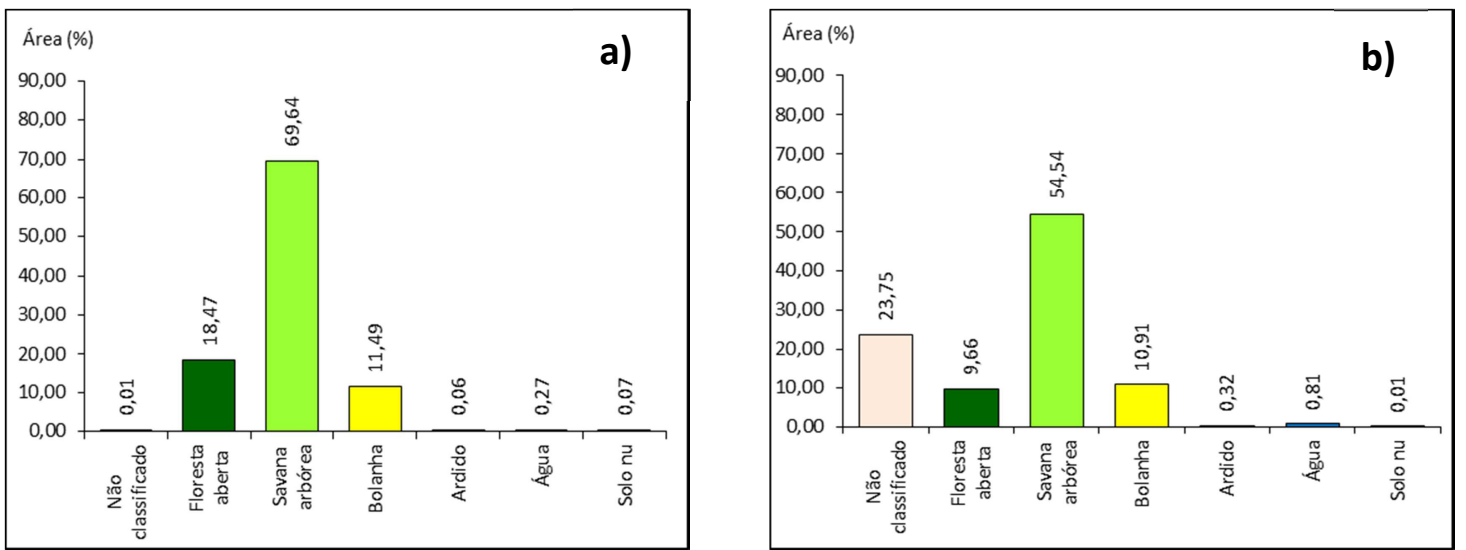

Figura 10 - Superfície ocupada pelos tipos de coberto do solo na área de estudo da fronteira leste: a) Guiné-Bissau; b) Guiné-Conacri. 
Resumindo, os tipos de coberto do solo predominantes são semelhantes em ambos os países e são essencialmente savana arbórea, floresta aberta e bolanha (figura 10). A rede viária e a distribuição das aldeias dispõem-se paralelamente ao longo da linha de fronteira, em parte condicionada pelo vale encaixado do rio que a delimita (figura 8b).

\section{Discussão e conclusões}

Este estudo, baseado na análise topológica de redes, mostra que a densidade da rede viária, o número de aldeias, a acessibilidade entre elas e a conectividade da rede são semelhantes na Guiné-Bissau e nos países limítrofes, embora com contrastes bem marcados conforme o sector da fronteira.

Apesar de nas duas áreas de estudo existirem cursos de água nas regiões de fronteira, estes não exercem uma influência significativa na acessibilidade entre as aldeias dessas áreas. Por outro lado, verifica-se que nas duas e sobretudo na leste, com a Guiné-Conacri, grande parte da rede viária tem continuidade entre os dois países vizinhos e os cursos de água não constituem qualquer barreira.

Entre os países limítrofes, nas duas áreas, uma estrada principal constitui um importante eixo de tráfego e um número semelhante de eixos viários cruzam a fronteira. Nos dois casos as redes de estradas são bem estruturadas, com boas ligações a nível interno de cada país e entre países.

No conjunto, as aldeias em que existe uma maior concentração de ligações, acessibilidade e centralidade são coincidentes (figuras 5, 6 e 7). Este facto leva a concluir que sendo as ligações directas ou indirectas, entre os nós da rede, as aldeias mais acessíveis são praticamente as mesmas. No entanto, as medidas de análise interna da rede (acessibilidade e centralidade) reflectem melhor o seu impacto no território do que as de análise da estrutura geral (conectividade e de ligação), dado que analisam sobretudo os nós e não apenas a rede em geral.

Verifica-se, assim, que a fronteira não influencia significativamente a continuidade da rede viária nem a acessibilidade entre as aldeias de países vizinhos, nem mesmo quando é delimitada por cursos de água. Tendo em conta o comportamento do coberto do solo, a 
fronteira também não constitui uma barreira, pois, na realidade, os vários tipos e a sua distribuição espacial tem continuidade transfronteiriça quer a norte quer a leste, embora mais evidente entre a Guiné-Bissau e o Senegal

\section{Referências}

Amaral, I. (1985). Fronteiras, estado e nação em África. Apontamentos de geografia política. Lisboa, Memórias da Academia das Ciências de Lisboa, Classe de Letras: 43-68.

Amaral, I. (1994). New reflexions on the theme of international boundaries. Global boundaries. World boundaries. Scholfield, C.H. (ed). Londres, Routledge, 1: 16-23.

Amaral, I. (1995). A Africa no limiar do século XXI: um continente em crise. Enciclopédia Luso-Brasileira de Cultura Verbo, Lisboa, Editorial Verbo, 23: 387-418.

Arragain, F. e Salliot, E. (2006). Forums de dialogue transfrontalier. Frontière Sénégal - Guinée Bissau. Frontières et Intégrations en Afrique de l'Ouest, $35 \mathrm{p}$..

Costa, F.L.; Melo, A.R.; Cabral, A.I. e Nunes, M.C.. (2014). Acessibilidade e povoamento nas regiões de fronteira da Guiné-Bissau. Guimarães, Actas. XIV Colóquio Ibérico de Geografia, 'A Jangada de Pedra'. Geografias IberoAfro-Americanas, 6 p..

Dione, I. (2013). Santé et territoire en Haute Casamance: Logiques socio-économiques et territoriales d'accès aux soins dans un espace commun à la Gambie, la Guinée Bissau, le Sénégal et la Guinée. ESO, Travaux \& Documents, 36: 67-77.

Döpcke, W. (1999). A vida longa das linhas retas: cinco mitos sobre as fronteiras na África Negra. Revista Brasileira de Política Internacional, 42 (1): 77-109. (http://pt.scribd.com/doc/52967155/HG-Cinco-mitos-sobreas-fronteiras-da-Africa).

Fanchette, S. (2001). Désengagement de l'état et recomposition d'un espace d'échange transfrontalier: la Haute-Casamance et ses voisins. Autrepart, (2001/3), 19: 91-91. DOI : 10.3917/autr.019.0091.

Michalopoulos, S. e Papaioannou, E. (2011). The long-run effects of the scramble for Africa. National Bureau of Economic Research, Working Paper 17620, 72 p. (http://www.nber.org/papers/w17620).

Murdock, G. P. (1959). Africa: Its peoples and their culture history. McGraw Hill Text. In: http://peterslarson.com/2011/01/19/african-conflict-and-ethnic-distribution/ (16-5-2012).

Shimbel, A., (1953). Structural parameters of communication networks. Bulletin of Mathematical Biophysics, Vol. 15.

Sousa, P. (2010). Efeito estruturante das redes de transporte no território. Modelo de análise. Doutoramento em Geografia Humana, Instituto de Geografia e Ordenamento do Território, 313 p..

Tam-Tam. (2009). Tam-tam. O eco da actualidade transfronteiriça. Procas e Enda Diapol, № 1-2, 3 e 4.

Tomás, J. (2010). Porqué un rey joola cruza la frontera y el outro no? Pinceladas sobre una investigación en curso en la frontera entre Guinea-Bissau y Senegal. Lisboa, 7o Congresso Ibérico de Estudos Africanos, 13 p..

Vasconcelos, M.; Cabral, A.; Melo, J.; Pearson, T.; Pereira, H.; Cassamá, V. e Yudelman, T. (2014). Can blue carbon contribute to clean development in West-Africa? The case of Guinea-Bissau. Mitigation and Adaptation Strategies for Global Change, 23 p.. 